\title{
Dendrodendritic synapses: past, present and future
}

\author{
Gordon M. Shepherd \\ Department of Neurobiology, Yale University School of Medicine, 333 Cedar Street, New Haven, \\ CT 06510
}

\section{Abstract}

Synapses between dendrites are at the core of mechanisms for processing odor stimuli, as well as for processing in many other brain systems. A perspective on the development of our understanding of these mechanisms may therefore be of interest. Studies of the olfactory bulb leading to the discovery of dendrodendritic synapses began in 1959. They involved a multidisciplinary approach that included Golgi cell morphology, electrophysiology, a microcircuit wiring diagram, membrane biophysics, theory of field potentials, cable theory, dendritic electrotonus theory, computational models of mitral and granule cells, prediction by the models of dendrodendritic synaptic interactions, confirmation with electron microscopy using single sections and serial sections, and final integration in the reports of feedback and lateral inhibitory interactions in 1966 and 1968. Following the discovery of glomerular odor maps in the 1970s, the functional significance of the dendrodendritic inhibition in processing the maps has been increasingly documented. Recent experimental and computational studies are revealing how these synapses are organized into distributed systems for processing the odor maps. Future studies need to situate dendrodendritic mechanisms in these distributed systems and correlate them with the tight functional loops between olfactory bulb and olfactory cortex. Studies in awake behaving animals will be increasingly important. The relations of dendritic mechanisms to perception, memory, and the pathogenesis of disorders such as Alzheimer's will be rich fields for study. Dendrites and their synapses should continue to provide ideal models for the study of basic mechanisms of cortical integration and the neural basis of smell.

\section{Keywords}

dendrodendritic synapses; reciprocal synapses; mitral cells; granule cells; dendritic spines; active dendrites; cortical columns; lateral inhibition; olfactory discrimination; cortical microcircuits; computational modeling; multidisciplinary research

\begin{abstract}
A half-century perspective on synapses between dendrites provides an opportunity to discuss with a new generation of investigators how the discovery was the result of a multidisciplinary effort, the steps that have brought us to our current concepts, and thoughts on what may be some fruitful directions to take us into the next half-century. Although the story began almost 50 years ago, the events are as fresh as if they happened yesterday.

Shortly before entering medical school, stimulated by reading Norbert Wiener's book on "Cybernetics", I decided I wanted to work on the neurophysiology of cells in the cerebral cortex. After four years of medical school, the chance came when I was incredibly lucky to be invited to do this in the laboratory of Charles Phillips in Oxford. He could have been in Timbuktu and I would have gone there. His undergraduate mentor Jack Eccles had been the
\end{abstract}

Address for correspondence: Gordon M. Shepherd, Department of Neurobiology, Yale University School of Medicine, 333 Cedar Street, New Haven, CT 06510. Voice: 203-785-4336, fax: 203-785-6990. gordon.shepherd@yale.edu. 
first to record intracellularly from a neuron in the central nervous system, the spinal motoneuron, and begin to work out the circuits for excitation and inhibition that control it in the spinal cord. Phillips in turn was the first to record intracellularly in the brain, from pyramidal neurons in the cortex. It took fierce determination, developing the methods to record from cells in the pulsing brain of the cat and primate.

As it happened, by the time I got there Phillips was stimulating the cortex but recording from motoneurons supplying the muscles of the hand in the primate, work that was seminal for our understanding of fine motor control. If I had joined in that work I would be telling another audience what I had gleaned during my life about the cortical control of movement, but I allowed as how I really had a hankering to work on circuits in the cortex itself. With extraordinary generosity, he told me that in that case there was a nice model system waiting to be analysed - the olfactory bulb. His colleague in anatomy, Tom Powell, had worked on the anatomy of the limbic system, and noticed that the separation of input and output pathways in the olfactory bulb made it an ideal subject for selective stimulation of those pathways, in order to work out the intrinsic circuits inside. When I evinced interest, he sent me off to read Cajal, and I was hooked. Those images of the cells in the olfactory bulb were tantalizing mysteries, about which nothing was known; my challenge was to find out, as a model for how a cortical region is organized.

Experiments then were all done in vivo. Phillips worked with me in developing the new preparation of the anesthetized rabbit, with exposure of the lateral olfactory tract for antidromic stimulation of the olfactory bulb and single cell recordings of responses in the olfactory bulb. By Christmas we had revealed strong recurrent inhibition of presumed mitral cells. He then felt confident in turning the project over to me for a graduate thesis. It is a strategy I've used subsequently when someone in the lab has launched into a new project, so that the mentor has intimate knowledge of the problems and is confident that they can be solved.

It was extremely fortunate that Powell had just returned from eight months in Baltimore, where he worked with Vernon Mountcastle to produce the classical papers in 1959 on the anatomical basis of the cortical columns that Mountcastle had characterized physiologically. Tom and I worked together to apply his same methods to the olfactory bulb in order to correlate the changes in field potentials with depth, which led to identification of the changeover from large negativity to large positivity at the layer of mitral cell bodies. This has been a useful guide for later investigations, as well as playing a critical role in the dendrodendritic story.

For the single cell recordings our methods reflected that it was still at the dawn of the microelectrode era. We drew our micropipettes by hand in a microforge, pulling out the glass tubing to successively smaller diameters down to a micron or so, then filling them by boiling in potassium solution. Fortunately, the Tektronix 502 oscilloscope had arrived in England, together with cathode followers and stable stimulating electronics. Recordings of the traces were made on film with a Grass movie camera. The mortal danger was to have the greatest experiment and discover that you'd forgot to remove the lens cap!

Phillips had arranged for assistance in the laboratory by Charles Carr, an older gentleman who, I was honored to learn, as a lad in the 1930s had been the last technician of Charles Sherrington. Phillips was all business in the laboratory. He adhered to the old German doctrine of "When I come into the laboratory in the morning I leave my thinking cap on the peg outside with my coat"; in other words, we're here to do experiments. The other dictum I summarized as "Every result is artefact until proven otherwise". I've been guided by both ever since. 
Over three years of experiment and analysis, we characterized action potential generation and synaptic responses of each of the main types of cell in the olfactory bulb. At the end, one of my thesis examiners, George Gordon, suggested I should make a diagram of the connections I was proposing. This resulted in the diagram published in 1963 (1).

As far as I know it was among the first, if not the first, such wiring diagram for the local circuits in a region of the brain. In it we proposed the pathways for antidromic as well as orthodromic activation of the main cell types. From the latency measurements we proposed that granule cells were activated by axon collaterals from the mitral cell axons, and that they would function like Renshaw cells in the spinal cord to mediate the recurrent and lateral inhibition of the mitral cells that we had found. It was the first evidence for a neuronal function of the granule cell. Von Baumgarten and Yamamoto also found the inhibition, but did not propose a pathway.

At the end of the three years, in 1962, the first ISOT meeting was held in Stockholm. Someone arranged for me to be invited, but I didn't get on the program. The meeting was organized around the psychophysics of taste and smell. The buzz was about the exciting results of Bob Gesteland, Jerry Lettvin and their colleagues reporting the first single cell recordings from vertebrate olfactory receptor neurons.

The distinct field potentials generated in the olfactory bulb by antidromic action potentials suggested to me that they might be of interest to Wilfrid Rall, who had published several papers in his pioneering biophysical analysis of dendrites and the potentials that they generate, mostly in motoneurons. It seemed like a long gamble, but again, I was incredibly lucky. He was interested, and Grethe and I moved to Bethesda in the fall of 1962 for me to work with Rall in the Mathematical Research Branch at NIH. The first month we were without income while I took the exams for entering the Public Health Service and waited for the results and official approval; fortunately I passed. One has to take risks, but I knew I was fortunate to have not only Rall but also Kay Frank and Wade Marshall, two giants of neurophysiology at $\mathrm{NIH}$, supporting me.

Rall, a physics major at Yale who worked briefly on the Manhattan Project, had trained in neurophysiology with Eccles and McIntyre in New Zealand, so I was twice in the Eccles lineage, and working again in a motor physiology laboratory. As at Oxford, we didn't think of the olfactory bulb in relation to its function in smell, but rather as a simple system for understanding dendrites and cortical organization.

Many people cautioned me against taking two years from experimental work to do only theory, but I had grown up during the era of the atomic bomb, learning about how physics needed both experimentalists and theorists, and thought that this should apply to working on the nervous system as well. I wasn't much of a mathematician, but Wil was very interested in the data, to which he could apply his theoretical approach, and we quickly found out we were both low key and enjoyed working together. I had the overconfidence of youth that I knew more about the physiology of the olfactory bulb than anyone else, and Wil certainly knew more about the functional significance of dendrites than anyone else.

Even before I arrived he had developed the concept of a "potential divider" to account for the current flows around the activated cells in the olfactory bulb. Most importantly, in the first month he attended a symposium at which he presented for the first time his new "compartmental method" for computational simulation of activated nerve cells (re-published in 2). This gave us an entirely new approach for designing a compartmental representation of mitral cells and granule cells to explore how they might account for the field potentials, and at the same time for the pathway mediating the inhibition of the mitral cells. 
For the next two years we worked on developing models for an action potential in the mitral cell, as well as an initial excitatory followed by inhibitory postsynaptic potential in the granule cell. It was the first time that these properties had been investigated in dendritic models of both a principal neuron and an interneuron (the motoneuron models involved the soma and dendrites of a principal neuron). Although this showed how the antidromic action potential invades far into the dendrites, and how synaptic potentials are generated and spread in the dendrites, it left uncertain the pathway for the synaptic interactions. In my wiring diagram I had supposed that deep axon collaterals would activate the granule cells, which would then inhibit the mitral cell secondary dendrites, but that route didn't fit with localization of the field potentials. We were beginning to feel that the modeling wasn't telling us much more than we knew already.

Wil kept a protocol book in which he wrote down at the end of each day a summary of the runs and calculations, of our interpretations, and our predictions for the next day's runs. About a month before I was to leave, on August 24, 1964, we were writing down a summary of what we knew and didn't know. As we talked about the action potential in the mitral cell, we hypothesized, on the basis of the field potentials, that the action potential invaded the lateral dendrites just above the mitral cell body layer, at a time just before the onset of the inhibition of those same dendrites by the granule cell dendrites. While puzzling over what the possible pathway might be for granule cell excitation, we looked at each other and thought: what if the granule cell dendrites are excited by the same mitral cell lateral dendrites that they then inhibit? This would imply side-by-side contacts mediating mitral-togranule cell dendrite excitation followed by granule-to-mitral cell dendrite inhibition. Our notes included the hypothesis that "this inhibition would focus "lateral" or "surround" inhibition and should serve to sharpen contrast." Wil summarized this circuit in his protocol book, using the term "dendrodendritic" for the first time. It was only a few years after the first synapses were identified in the electronmicroscope, so we didn't know what form "dendrodendritic" synapses might take.

As part of the work with Wil, I had undertaken a histological study of the olfactory bulb to assess the packing density of the mitral cells in order to quantitate the current density around them. During this study in Building 9 at NIH I met Tom Reese and Milton Brightman there who were doing an EM study of the olfactory epithelium, after which they planned to move on to the olfactory bulb. We had a number of meetings, during which I told them about our computational study, and raised with them the possibility of doing a multidisciplinary project together, combining physiology, computation, and electron microscopy. I urged them to look for interconnections between mitral and granule cells, and told Wil about Tom and Milton, to keep in touch on their progress.

I then left for Stockholm and a two year stint with David Ottoson, to begin to learn about the physiology of smell. Wil kept working on the model and Reese and Brightman kept working on the EM. In January 1965 Tom wrote me that they had found what appeared to be "dendrodendritic synapses" in the olfactory glomeruli. Then in March Wil wrote me (all this correspondence was by air mail letter) that he had attended a seminar by Tom in which Tom had presented their first EM results on the olfactory bulb, with the finding of side-by-side dendrodendritic synapses between presumed mitral and granule cell dendrites, but without being able to explain what their function might be. Wil immediately described how their synapses fit our model for recurrent and lateral inhibition of the mitral cells. Thus, it's important to emphasize: the model came first, predicting novel synaptic interactions; it was not, as is so common today, that a model is made afterwards to simulate an anatomical or physiological result. 
There had been no precedent for this type of interaction anywhere in the nervous system (the synapses had also been seen but not functionally interpreted by Hirata (3) and Andres (4)). It was against the neuron doctrine, that axons only have output synapses and dendrites only input synapses. The interactions mediating lateral recurrent and lateral inhibition clearly must be important in sensory processing in the olfactory bulb. We wrote up the results, with beautiful EMs by Tom and Milton, including definitive identification of the dendrites with painstaking serial sections, and an outline of our physiological and novel computational analysis, and the implications for how neurons can interact to mediate lateral inhibition through their dendrites. We submitted the paper to Science in the summer of 1965. It came back flatly rejected: "not of general interest".

Wil was too courteous to raise strenuous objections and fight for further review as is the custom today. Instead, he submitted it to a relatively new journal, Experimental Neurology, which published it in early 1966 (5). After I came to Yale in 1967 we continued to collaborate to finish a longer paper on the computational model, which was published in the Journal of Neurophysiology in November 1968 (6) (Figure 1). It was just 9 years after I had got the first recordings of inhibition at Oxford.

For current modelers, a few points may be interesting. First, our model was made on a mainframe machine, the Honeywell 800, achingly slow by modern standards. Every afternoon we decided on which parameters to change, and got the run back from the Holleywell at the computer center the next morning. Despite the slow pace, this had several advantages. Perhaps most importantly, it forced us to think carefully about each run, predicting the value of the result, making a printout the next day for continued study, and entering the results and our discussion in the protocol book. In contrast, today dozens of runs can be churned out in the course of an hour or a day, critical predictions are seldom made, and versions are usually ignored or lost.

Second, the model was relatively simple, with only a dozen or so compartments for each neuron type, and a reduced Hodgkin-Huxley-type model for the action potential and conductance-increase models for the synaptic potentials. But the models captured the essential principles, an approach Wil introduced early in his theoretical work. In contrast, current models composed of hundreds or thousands of compartments can more obscure the principles than reveal them.

A third point is that interest in modern models is focused exclusively on compartmental representations of intracellular potentials. Field potentials are rarely included, yet they provided us with valuable clues in our analysis. Field potential analysis today usually is replaced by current source density analysis, but this is ultimately based on the recorded field potentials, and we were able to obtain essentially the same information from our reconstruction of the currents underlying the field potentials.

The new wiring diagram made explicit how the circuit functions similarly whether antidromically or orthodromically activated, so that it could be applied directly to odor processing. In addition, the synaptic interactions between dendrites had a somewhat amazing number of implications for neuronal circuit organization in general. Among the new concepts, it gave a function to a backpropagating action potential (in the mitral cell). It solved the problem of the neural function of an axonless cell (the granule cell). In the granule cells, it further showed how a neuron could function without a propagating action potential. It gave a specific function to dendritic spines. It demonstrated how a neuron can contain local computational units within its dendritic tree (both output neurons and interneurons). All of these concepts have become part of our thinking about neuronal organization in general. 
At about this same time John Dowling and Brian Boycott were carrying out their EM studies of the retina, which showed non-traditional interconnections between retinal processes, including "reciprocal synapses" equivalent to dendrodendritic synapses (7). This was followed in 1969 by the landmark study of Frank Werblin and Dowling (8) on the physiological responses of the retinal neurons, shortly after our paper provided the model of mitral-granule interactions. Soon EM studies of synaptic organization were being carried out for the first time in a number of central brain regions. In addition to the expected synapses by axon terminals on cell bodies and dendrites, a number of instances were found of dendrodendritic synapses, including the main relay nuclei of the thalamus, the dopaminergic cells of the substantia nigra, and the neurons of the locus ceruleus. These specific patterns of synaptic interactions all seemed to be variations on the themes seen in the olfactory bulb and retina, and suggested that they might function in the nature of neural "microcircuits" (9).

Over the intervening years the dendrodendritic model has been subjected to repeated testing, experimentally and computationally. Roger Nicoll provided one of the first tests (10). Later Martha Nowycky $(11,12)$ and Kensaku Mori $(13,14)$ introduced the isolated turtle olfactory bulb to document in considerable detail with intracellular recordings the strong action of lateral inhibition. Craig Jahr and Nicoll (15) adopted this preparation and provided clear evidence for both lateral inhibition and feedback inhibition, that is, the ability of an activated mitral cell to feed back inhibition onto itself. Kensaku, Martha and I puzzled over our inability to demonstrate this feedback inhibition. Only later, after the NMDA receptor was identified, did we learn, chatting with Roger, the reason for the difference. We had carefully followed precedent in including $\mathrm{Mg} 2+$ in our bath, whereas they took some available Ringer solution for their bath which happened to be $\mathrm{Mg} 2+$-free. So our preparations had blocked NMDA receptors, whereas they had preparations with powerful activation of the feedback circuit through NMDA receptors. Such is biology.

Further electrophysiological analysis of lateral inhibition has been consistent with the dendro-dendritic model; among early studies may be mentioned $(16,17)$.

Electronmicroscopic studies have provided repeated confirmation that the synapses between mitral cell dendrites and granule cell spines are mainly in reciprocal pairs (cf. 18). The synapses show plasticity in cases of specifically mitral cell degeneration in pcd mutant mice (19).

A new chapter in experimental analysis of dendrodendritic inhibition opened with the advent of dual patch recordings by Stuart and Sakmann (20). Nickel and Shipley (21) developed the isolated rodent slice which enabled these recordings to be applied to olfactory bulb dendrites. Chen et al (22) showed that action potentials could propagate in either direction in the primary dendrite, again showing in the olfactory bulb an exception to classical doctrine. Xiong et al (23) then showed that action potentials can propagate throughout the length of the lateral dendrites, a critical finding as we shall see for an expansion of the dendrodendritic model.

All of this work involved electrophysiological analysis of cell properties and interactions. What about their relation to olfactory processing? We have already noted that lateral inhibition was central to our concept of the functional significance of the dendrodendritic synapses. In a series of papers, Kensaku Mori's laboratory, using homologous chemical series, showed that a given mitral cell responds to a limited spectrum within a series (summarized in 24). Furthermore, this range is narrowed by inhibition from mitral cells activated by neighboring members of the series (25). They further showed that this inhibition is blocked by bicucculine, a blocker of inhibitory GABAergic synapses, and obtained evidence that it was acting at the level of the mitral and granule cell interactions. Their diagram was an application of the original model, to propose that dendrodendritic 
lateral inhibition sharpens the response spectra of individual mitral cells to their preferred odor molecules.

The original model assumed that inhibition was imposed on neighboring or nearby mitral cells. However, this idea began to change after the discovery that odor stimuli are represented by functional activity patterns in the glomerular layer (summarized in 26). These "odor maps" are the inputs that are processed by the dendrodendritic synaptic circuits. An in-depth consideration of odor maps is beyond the scope of this talk, but the key point is that, with global markers such as 2-deoxyglucose and f-MRI, these maps can be seen to involve extensive areas of the olfactory bulb (26). This has implied that lateral inhibition is likely to act quite widely in processing the maps (27), which contrasts with the relatively narrow fields of granule cell dendrites as depicted in our original model.

The solution to this question has come from two recent independent lines of investigation. One line has involved the use of pseudorabies virus to track synaptic connectivity in the olfactory bulb (28). These experiments have provided evidence for narrow columns of bulbar cells, especially granule cells, lined up radially over individual glomeruli. Critically, a single focal injection in the olfactory bulb or the olfactory cortex produces an ensemble of these columns arranged as a mosaic throughout much of the olfactory bulb. From this it has been concluded that mitral cells do not interact primarily with neighboring mitral cells, but rather with mitral cells belonging to columns that may be at varying distances from them.

If granule cell columns are narrow, how would lateral inhibition be imposed at a distance to process the odor maps? The second piece of evidence has come from a computational modeling study (29) that initially asked the question: how strong is lateral inhibition around a single activated mitral cell? The simulations indicated that strong inhibition at longer distances requires action potentials which propagate from an active mitral cell soma through the lateral dendrites. This gives a key function to what Xiong et al (23) had found. The lateral dendrite acts like an axon, propagating a non-decrementing action potential which equally activates all the granule cells connected to it over distances up to $1 \mathrm{~mm}$ or more. The activated granule cells in turn impose lateral inhibition on the mitral cells to which they are attached in the distant columns. A parallel study has tested a learning rule for developing this type of connectivity (30). The combined anatomical and computational results are shown in the modified microcircuit diagram of Figure 2.

Here again we see how a computational model can be used in a predictive way, exploring new types of connectivity and interactions that go beyond current evidence. In this case the anatomical evidence developed contemporaneously, but the principle of independent prediction of the type of connectivity revealed by the anatomical tracing is similar. Also similar, ironically, was the initial response to our manuscript with the new version of the model: "no significant advance". Plus ca change ....

In summary, the original dendrodendritic model has continued to be useful in understanding mitral-granule interactions and guiding further experiments. The revised model enables a mitral cell to mediate surround inhibition independently of distance. It predicts that the lateral dendrite is active as far as the inhibition extends. A high priority for the future will be to correlate the distribution of lateral inhibition with the distribution of the odor maps, as the basis for the non-topographical processing in the olfactory bulb.

I have focused here on the dendrodendritic synapses at the level of mitral and granule cells. A similar talk could deal with these types of synapses and their interactions within the olfactory glomeruli. Correlating the processing at these two levels has barely begun, and will be a major challenge for the future. 
In the symposium organized by Charles Greer that preceded this talk, there was a series of excellent presentations on current studies of the dendrodendritic interactions in the olfactory bulb, which are summarized in the following articles. Pierre-Marie Lledo highlights granule cell function within the context of the rapid turnover from the rostral migratory stream. Marco Sassoe-Pognetti gives us new images of the fine structure of the dendrodendritic synapses. Ben Strowbridge describes his analysis of the critical relations between olfactory bulb and olfactory cortex. Kensaku Mori shows new evidence regarding the relations between mitral cell lateral dendrites and glomerular areas of odor activation. Matt Ennis investigatea the relation between mGluRs and modulation of the dendrodendritic circuit. Finally, Nathan Urban reviewa the range of functions revealed by his laboratory and others.

These investigations give an intriguing view into the future. It seems safe to predict that fruitful interactions between experiment and theory will lead to new and unexpected functions for dendrodendritic processing. The focus up to now has been on lateral inhibition mediating contrast enhancement. In the original model we pointed out that the inhibition would also mediate synchronization of mitral cells and oscillatory behavior, a topic which has become of increasing interest and would merit a separate talk by other experts (cf. 31). Dendrodendritic inhibition in the olfactory bulb may also be involved in olfactory learning and memory (32). These studies in the olfactory bulb need to be combined with those in olfactory cortex in order to understand the tight functional loops between the two in odor processing; these loops pass through the dendrodendritic synapses. Methods applied to the awake behaving animal will give critical new insights. Finally, the roles of dendrodendritic mechanisms in perception, memory, and the pathogenesis of disorders such as Alzheimer's need to be pursued aggressively.

In summary, dendrites and their synapses should continue to provide ideal models both for the study of basic mechanisms of cortical integration and for the neural basis of smell. The frontier beckons; the next half-century should be even more interesting than the last.

\section{Acknowledgments}

Our work has been supported by NIDCD and the Human Brain Project.

\section{References}

1. Shepherd GM. Neuronal Systems Controlling Mitral Cell Excitability. J Physiol. 1963; 168:101-17. [PubMed: 14056480]

2. Segev, I.; Rinzel, J.; Shepherd, GME. The Theoretical Foundation of Dendritic Function. 1995.

3. Hirata Y. Some observations on the fine structure of the synapses in the olfactory bulb of the mouse, with particular reference to the atypical synaptic configurations. Arch Histol Jpn. 1964; 24:293302. [PubMed: 14133696]

4. Andres KH. The fine structure of the olfactory bulb in rats with special reference to the synaptic connections. Z Zellforsch Mikrosk Anat. 1965; 65:530-561. [PubMed: 14263015]

5. Rall W, et al. Dendrodendritic synaptic pathway for inhibition in the olfactory bulb. Exp Neurol. 1966; 14:44-56. [PubMed: 5900523]

6. Rall W, Shepherd GM. Theoretical reconstruction of field potentials and dendrodendritic synaptic interactions in olfactory bulb. J Neurophysiol. 1968; 31:884-915. [PubMed: 5710539]

7. Dowling JE, Boycott BB. Organization of the primate retina: electron microscopy. Proc R Soc Lond B Biol Sci. 1966; 166:80-111. [PubMed: 4382694]

8. Werblin FS, Dowling JE. Organization of the retina of the mudpuppy, Necturus maculosus. II. Intracellular recording. J Neurophysiol. 1969; 32:339-55. [PubMed: 4306897]

9. Shepherd GM. Microcircuits in the nervous system. Sci Am. 1978; 238:93-103. [PubMed: 204003] 
10. Nicoll RA. Inhibitory mechanisms in the rabbit olfactory bulb: dendrodendritic mechanisms. Brain Res. 1969; 14:157-72. [PubMed: 5783107]

11. Nowycky MC, Waldow U, Shepherd GM. Electrophysiological studies in the isolated turtle brain. Soc Neurosci Abstrs. 1978; 4:583.

12. Nowycky MC, Mori K, Shepherd GM. GABAergic mechanisms of dendrodendritic synapses in isolated turtle olfactory bulb. J Neurophysiol. 1981; 46:639-48. [PubMed: 7299438]

13. Mori K, Shepherd GM. Synaptic excitation and long-lasting inhibition of mitral cells in the in vitro turtle olfactory bulb. Brain Res. 1979; 172:155-9. [PubMed: 223736]

14. Mori K, Nowycky MC, Shepherd GM. Electrophysiological analysis of mitral cells in the isolated turtle olfactory bulb. J Physiol. 1981; 314:281-94. [PubMed: 7310692]

15. Jahr CE, Nicoll RA. Dendrodendritic inhibition: demonstration with intracellular recording. Science. 1980; 207:1473-5. [PubMed: 7361098]

16. Hamilton KA, Kauer JS. Intracellular potentials of salamander mitral/tufted neurons in response to odor stimulation. Brain Res. 1985; 338:181-5. [PubMed: 4027588]

17. Ezeh PI, Wellis DP, Scott JW. Organization of inhibition in the rat olfactory bulb external plexiform layer. J Neurophysiol. 1993; 70:263-74. [PubMed: 8395579]

18. Woolf TB, Shepherd GM, Greer CA. Serial reconstructions of granule cell spines in the mammalian olfactory bulb. Synapse. 1991; 7:181-92. [PubMed: 1882328]

19. Greer CA, Shepherd GM. Mitral cell degeneration and sensory function in the neurological mutant mouse Purkinje cell degeneration (PCD). Brain Res. 1982; 235:156-61. [PubMed: 7188319]

20. Stuart GJ, Sakmann B. Active propagation of somatic action potentials into neocortical pyramidal cell dendrites. Nature. 1994; 367:69-72. [PubMed: 8107777]

21. Nickell WT, Shipley MT, Behbehani MM. Orthodromic synaptic activation of rat olfactory bulb mitral cells in isolated slices. Brain Res Bull. 1996; 39:57-62. [PubMed: 8846109]

22. Chen WR, Midtgaard J, Shepherd GM. Forward and backward propagation of dendritic impulses and their synaptic control in mitral cells. Science. 1997; 278:463-7. [PubMed: 9334305]

23. Xiong W, Chen WR. Dynamic gating of spike propagation in the mitral cell lateral dendrites. Neuron. 2002; 34:115-26. [PubMed: 11931746]

24. Mori K, Yoshihara Y. Molecular recognition and olfactory processing in the mammalian olfactory system. Prog Neurobiol. 1995; 45:585-619. [PubMed: 7624486]

25. Yokoi M, Mori K, Nakanishi S. Refinement of odor molecule tuning by dendrodendritic synaptic inhibition in the olfactory bulb. Proc Natl Acad Sci U S A. 1995; 92:3371-5. [PubMed: 7724568]

26. Xu F, Greer CA, Shepherd GM. Odor maps in the olfactory bulb. J Comp Neurol. 2000; 422:48995. [PubMed: 10861521]

27. Cleland TA, et al. Relational representation in the olfactory system. Proc Natl Acad Sci U S A. 2007; 104:1953-8. [PubMed: 17261800]

28. Willhite DC, et al. Viral tracing identifies distributed columnar organization in the olfactory bulb. Proc Natl Acad Sci U S A. 2006; 103:12592-7. [PubMed: 16895993]

29. Migliore M, Shepherd GM. Dendritic action potentials connect distributed dendrodendritic microcircuits. J Comput Neurosci. 2008; 24:207-21. [PubMed: 17674173]

30. Migliore M, Inzirillo C, Shepherd GM. Learning mechanism for column formation in the olfactory bulb. Frontiers in Integrative Neuroscience. 2007; 1:1-7. Article 12. [PubMed: 18958229]

31. Laurent $\mathrm{G}$, et al. Odor encoding as an active, dynamical process: experiments, computation, and theory. Annu Rev Neurosci. 2001; 24:263-97. [PubMed: 11283312]

32. Kaba H, et al. Induction of an olfactory memory by the activation of a metabotropic glutamate receptor. Science. 1994; 265:262-4. [PubMed: 8023145]

33. Shepherd GM, Chen WR, Willhite D, Migliore M, Greer CA. The olfactory granule cell: from classical enigma to central role in olfactory processing. Brain Res Rev. 2007; 55:373-82.

[PubMed: 17434592] 
(A)
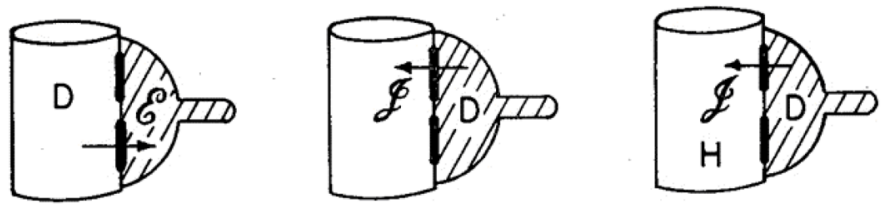

I - II

ㅍ-표

III

(B)

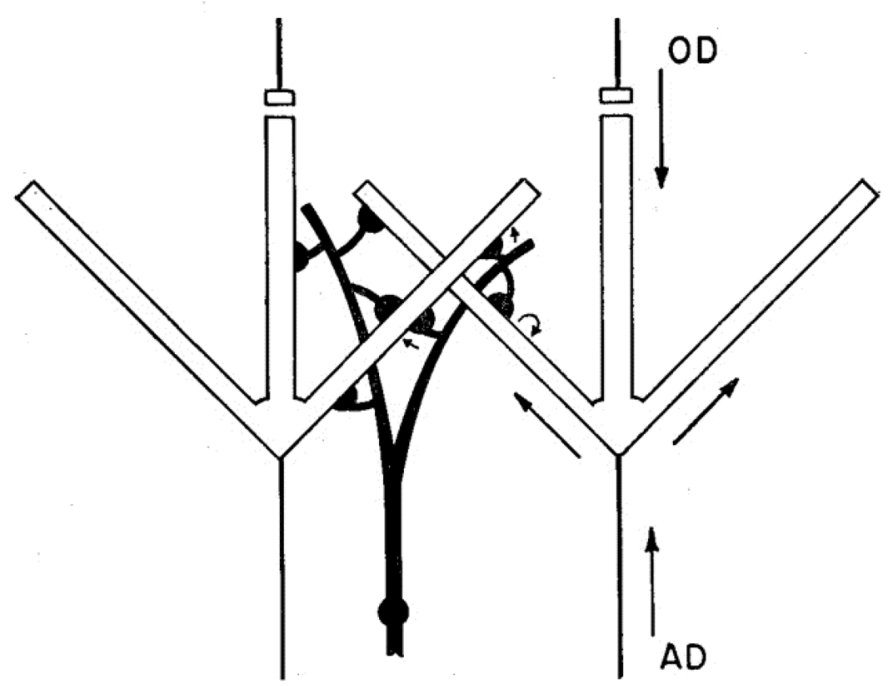

Fig. 1.

Model of dendrodendritic interactions between mitral and granule cells in the mammalian olfactory bulb, based on experimental evidence and predictions from computational modeling. A. Sequence of time periods I-III is shown after antidromic invasion of mitral cells. In time period I-II, a mitral cell dendrite (open profile) is depolarized (D) by invading action potential from the soma, activating excitatory (E) synapse onto granule cell dendrite (shaded). In time period II-III, the depolarized (D) spine activates an inhibitory (I) synapse back onto the mitral cell dendrite. This action continues into period III. B. Diagram showing how antidromic (AD) invasion of a mitral cell leads to lateral inhibition of a neighboring mitral cell through electrotonic spread of the granule cell depolarization within the granule cell dendritie tree. Orthodromic (OD) activation from the glomeruli through the primary dendrite leads to similar activation of the lateral dendrites and consequent feedback and lateral inhibition. From (6) 


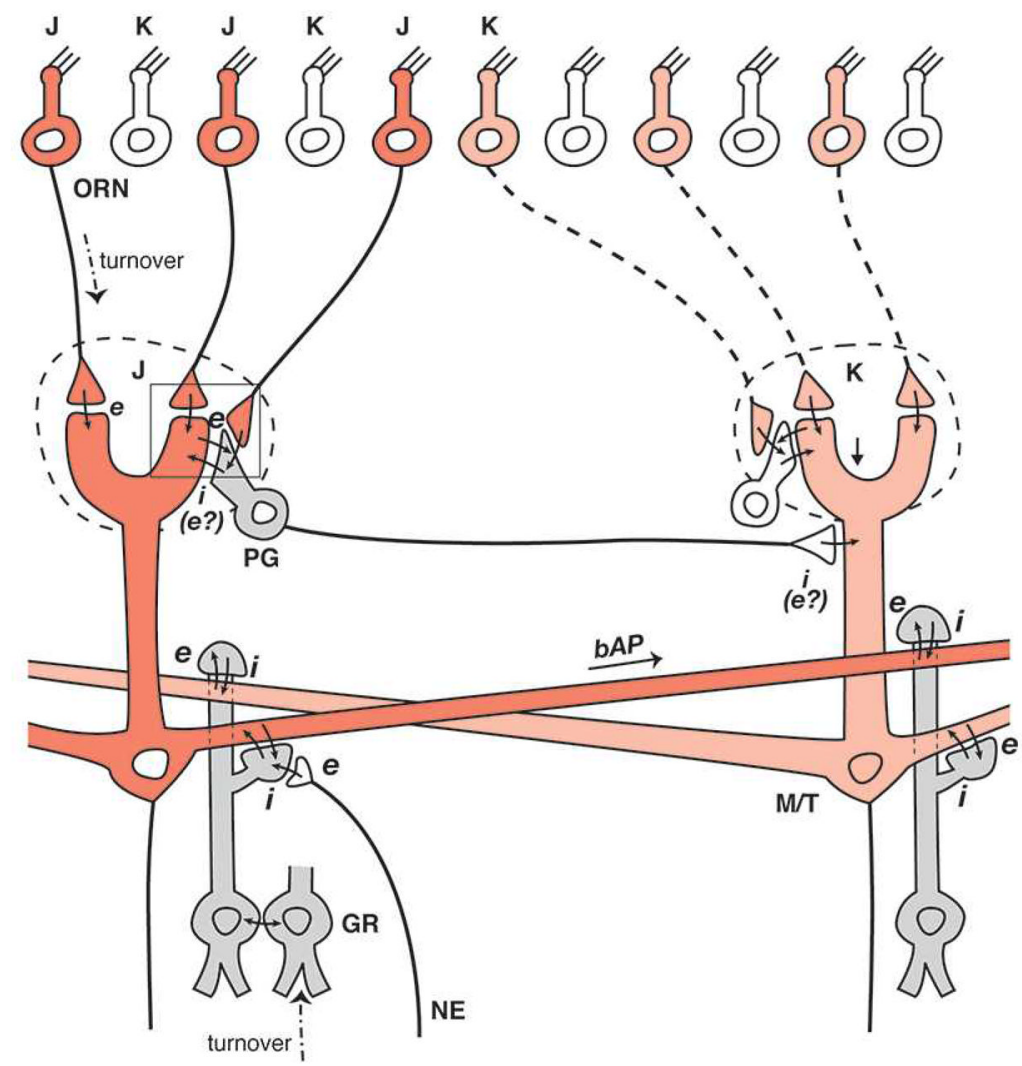

Fig. 2.

Incorporation of the original dendrodendritic circuit into glomerular units for widely distributed lateral inhibition in the olfactory bulb, based on recent studies (see text). Two glomerular units are shown, each consisting of a glomerulus receiving inputs from its olfactory receptor neuron $(\mathrm{ORN})$ subset $(\mathrm{J}, \mathrm{K})$ and connecting to a subset of mitral/tufted $(\mathrm{M} /$ $\mathrm{T})$ cells and their interneurons: periglomerular (PG) cells at the glomerular layer, and granule (GR) cells deep to the mitral cell body layer. A backpropagating action potential (bAP) in the left mitral cell lateral dendrite provides full activation of the granule cells within the glomerular unit on the right, independent of distance, to mediate "nontopographical" lateral inhibition in processing the distributed odor maps laid down in the glomeruli by the activated ORNs. Adapted from (33) 